\title{
Analyzing Tourist Behavior System in Sustainable Tourism
}

\author{
Luxsanan Ploywattanawong $^{1+}$ and Mayuree Sawatmuang ${ }^{2}$ \\ ${ }^{1}$ Rajamangala University of Technology Suvarnabhumi/Information Technology Department, Suphan Buri, \\ Thailand \\ ${ }^{2}$ Rajamangala University of Technology Rattanakosin/Business English Department, Bangkok, Thailand
}

\begin{abstract}
In Thailand, tourism is the key industry that drives the economy in the country. There have been many official policies announced to help to promote the tourist attractions. We studied the factors influencing the number of tourists. The existing studies showed that the factors such as transportations, goods and services, and attraction images are the most important factors. With the proliferation of information technology, a new website that serves each tourist could be constructed to help the tourists. However, the tourists cannot find the updated information in one place as there is no such a system deployed by the official. As the result, it makes Thailand tourism disadvantage when comparing to the tourism in another country. In this paper, we proposed the tourist behavior analyzes system that will help to provide the tourists a useful information. We developed the system and studied the tourists' behavior in Suphanburi province as it is most of the most visited province in Thailand. The system showed the users' satisfaction is excellent. The tourists could get an essential information they need before traveling.
\end{abstract}

Keywords: tourism, information analyzing system, sustainable tourism.

\section{Introduction}

In many countries, tourism is one of the industries that have the most income. Tourism has many benefits such as more employment, more income, more money distribution along the countryside, more investment, and more taxes. As the result, the economy in those countries is driven by the tourism. Thailand is the second the most visited country in South East Asia. The tourist industry in Thailand which including those in Singapore and Malaysia has significantly grown over the years. Furthermore, Thailand is one more advantage that it is a Gateway-to-ASEAN country since ASEAN Economic Community is formed within the year 2016. Therefore, since most of the tourists can visit Thailand before spreading to its neighbors such as Cambodia and Myanmar, the government has deployed the strategic plan on tourism [1,2].

According to the Thailand Strategic Plan on sustainable tourism, the government plans to develop a tourism using sustainable economy [3] by strengthening local communities to be proud of the traditional knowledge and be able to welcome the tourists. However, one of the problems in Tourism in Thailand is the tourist information. Many tourists could not find the updated information in one place where the tourist can get enough information on their own and understand the context of the place they plan to visit. This information was a plan to be supported by the government [4] as information technology, and telecommunication has been developed throughout the country. Information technology such as a website can be essentially used to advertise and give basic information to the tourists before visiting the places. In addition, a more advanced information system can be deployed to analyze. However, none of the discrete systems has been developed to mitigate such as problem. As the result, it makes Thailand tourism disadvantage when comparing to the tourism in another country.

In this paper, the tourist behavior analyzes system is introduced to analyze the tourist behavior to study the tourist behavior by integrating knowledge from different areas such as Tourism, Psychology, Statistical Mathematics, and Information Technology. In the proposed system, we made a decision support system that

\footnotetext{
+ Corresponding author. Tel.: +6695-5241798.
}

E-mail address: luxsanun29@gmail.com 
supports the tourism according to the strategic government plan by surveying, developing the database, and analyze the tourist behavior. The proposed system creates a new channel for the tourists to find a multilanguage suitable website in one place in the sample province. We developed our prototype using the tourist data from Suphanburi province first. Because Suphanburi province is one of the most beautiful provinces that gains attention in tourism. Furthermore, traveling to Suphanburi takes only a few hours from Bangkok. The number of tourists in Suphanburi province has significantly increased from 10 million to 26 million people during the last 15 years [9]. However, no information system was deployed to support the tourist attractions in the province even the individual website of the places [10]. Therefore, we designed the generalized system that can be customized and adjustable to each visitor's need. The samples were collected from the tourists who have been in Suphanburi province to make a sample database. The contribution of this work is to develop the self-adjustable system that understands the tourists' need so as to improve the tourism in Suphanburi province. As the result, the local communities can benefit from the increased income as the number of tourists increases.

In this paper, the contents are organized as follows. First, the problems of the sustainable tourism were discussed in Section 1. Then the strategic plan issues by the government, the sustainable economy, and the theories used in the work are explained in Section 2. In Section 3, the proposed methodology is elaborated. Finally, the conclusions are made in Section 4.

\section{Literature Review}

In this section, we will discuss the existing works in three groups which are related official tourism strategic plans, Philosophy of Sufficiency Economy, and existing analytic methods.

\subsection{Strategic tourism plans}

The official tourism strategic plans are the tourism plans issued by the government and an international organization that would support the tourism throughout the country. There are two groups of the strategic plans. First is the plan the cooperated and supported by Association of Southeast Asian Nations (ASEAN) while the other plan is Thailand Tourism plan that is officially issued and used to develop the tourism in the country.

\subsubsection{ASEAN tourism plan}

ASEAN is a political and economic organization of 10 countries in Southeast Asians. ASEAN contains three main cores that are ASEAN Political-Security Community, ASEAN Socio-Cultural Community, and ASEAN Economic Community. The purposes of ASEAN are mainly declared so as to improve the economic growth, culture development, and social agreement, peace and stability of the membership countries. By the end of 2015, all the membership countries will have a tight cooperate among the countries by declaring ASEAN Economic Community (AEC) which will economically integrate with the world economics. The tourism industry will also be one of the supported industry. With the AEC agreement, all the membership country will have a free-trade area including goods, investments, and humans. This agreement would freely allow the tourist to travel around in membership countries.

There are four strategic plans agreed in ASEAN leadership conference. First, ASEAN Tourism Strategic Plan 2011-2015 is the plan that analyzes the tourism in ASEAN situation, vision, and structure of the tourism development.

Second, ASEAN Tourism Marketing Strategy 2012-2015 is the plan that pushes the tourism in ASEAN to worldwide tourism by improving competitiveness in tourism. It helps the membership countries to create an ASEAN brand to worldwide tourists by developing services and goods in tourism and creating a channel directly to the customers.

Third, ASEAN Framework Agreement on Services is the agreement on cooperating with international services so as to improve the competitiveness of the service providers. This agreement also reduces the hindrances on spreading the services to another membership country such as enabling a free-trade area. A free trade zone covers in many fields such as business, professional, construction, retail, education, services, environment, logistic, telecommunication, and tourism. 
Finally, ASEAN Mutual Recognition Arrangement on Tourism Professionals is the agreement that determines the competency standards for tourism professionals so that a tourism professional can freely work on the membership countries.

\subsubsection{Thailand tourism plans}

Five strategic plans are related to the tourism in Thailand. First, the 11th National Economic and Social Development Plan is the national plan used during the year 2012 and 2016. The plan determines 6 aspects of important strategy which are strategy for promoting a just society, strategy for human development toward a sustainable lifelong learning society, strategy for strengthening the agricultural sector \& food and energy security, strategy for restructuring the economy toward quality growth and sustainability, strategy for creation of regional connectivity for social and economic stability, and strategy for managing natural resources and environment for sustainability.

Second, Thailand Service Sector Development Strategy is the plan to develop the service sector to improve the potentiality and value added and makes more income to the country. The plan determines on four aspects of important strategy which are strategy for product and value creation, strategy for long-term quality growth, strategy for favorable investment climate, and strategy for income generation and quality of life for broad-base development.

Third, the Thailand's National Tourism Development Master Plan 2012-2016 is the plan that focuses on improving the tourism in Thailand into the Top-5 destination in Asia. The master plan has focused on five strategies which are 1) Development infrastructure and logistics, linking with among tourism places. 2) Development of tourism sites and improvement of rules and regulations to increase the country's capability for accepting more tourists. 3) Development of the creative economy which complies with the 11th National Economic and Social Development Plan. 4) Enhancement of confidence in Thailand's good image among visitors. 5) Participation in the public sector, civil society, and local administrative organization in tourism management.

Fourth, Tourism-Sport Ministry Strategy is the plan that promotes and develops tourism, sports, and recreation and results in efficiently integrating the events and budgets with another department. The plan focuses on 5 strategies which are strategy for goods and services development on quality and safety, strategy for stability and quality growth of the tourism, strategy for supporting and developing sports to healthy citizens, strategy for supporting and developing sports in education system, strategy for supporting and developing sport and sport science to sport professionals, and strategy for managing and supporting creative economics on tourism and sport.

Finally, Tourism and Travel related Services Strategic Plan is the plan that ensures the effective responses to the free-trade area on tourism and travel-related services. This plan was proposed to deal specifically with the tourism general in the country. The plan composes five strategies which are establishing a tourism knowledge management center, creating a capacity building program for tourism small-medium entrepreneurs, providing better education and training for tourism workers, creating a capacity building program for the department of tourism, and developing innovative and integrated tourism destination planning and management approaches.

As we study tourism strategic plan on national and international, we found that tourism in Thailand is a key industry to drive the country. Therefore, the proposed system must comply with the official strategy so as to be the main template for another department to deploy and develop the tourism.

\subsection{Philosophy of sufficiency economy}

Philosophy of Sufficiency Economy [8] is the philosophy conceived by His Majesty King Bhumibol Adulyadej. Since the modern development has caused the changes in Thai society especially economic and the significant growth of economy and rise of consumerism, the lives of Thai people heavily depend on the economy which dissolute the kinship and traditional knowledge. The concept has the thinking approaches as follows. First, Sufficiency Economy is essentially based on the principle of traditional Thai culture and can be applied all the time. Second, Sufficiency Economy can be applied to all groups and all ages of people. Third, Sufficiency must contain three pillars which are moderation, reasonableness, and risk management. 
Fourth, the condition used when making a decision should base on knowledge and virtue. Fifth, the outcome of applying this philosophy is balance and sustainable development in all aspects including economy, social, environment, knowledge, and technology.

Tourism regarding Sufficiency Economy is the sustainable tourism that is suitable for farmer society in Thailand [7]. In this context, as shown in Figure 1, farmers do not only farm rice, but also raise another plant to increase their income. They also do the business with a sustainable development and sufficiency economy. Tourism sector can cooperate with local communities and benefit together such as tourism business within a local community that does the business with room services, restaurants, healthy drinking shops, souvenir shops, transportation services, spa, Thai massages, and Thai cooking.

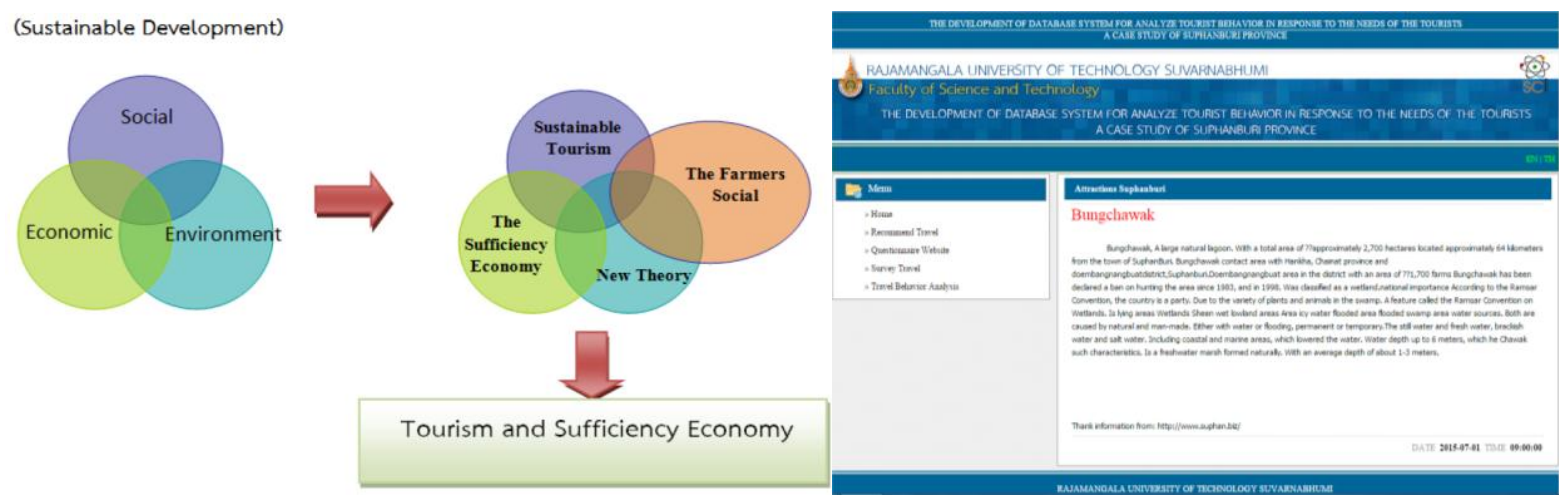

Fig. 1: Integration tourism in term of sufficiency economy.

Fig. 2: The website homepage.

\subsection{Existing analytic methods}

Analyzing data is one of the essential steps in qualitative research especially choosing the best method to analyze. Since many existing studies $[12,13,14,15,16,17,18,19,20,21,22]$ collected the primary data from the tourism attractions in Thailand using surveys, we also collected the primary data using the sample survey method. Furthermore, we also collected the data from in-depth interviews, and conversation with the focus group as mentioned in [11]. Exacting the useful information takes four steps as follows. First, indexing the data from the sources to make a set of keywords. Second, clustering the data by subject and question, and creates a sub-index that groups by influence and hindrance factors. Third, Drawing diagrams from each theme. Finally, the conclusions are verified.

According to the existing studies, Pizam and Sussmann [16] found that the tourists' behavior is affected by the nationality. Lew and Mckercher [17] found that the transportation planning, product and image development of tourist attractions, impact management. Shoval and Isaacson [19] studies the tourist behavior using a GPS tracker system. Then Shoval et al. [18] proposed that the business location and tourist events be the influence factors for the tourists. Assaf and Agbola [21] found that the hotel sector is one of the most effective industry if the government policy is announced to promote the tourist attractions. Ye et al. [22] found that the perceived quality and value of the hotels are significantly affected by the price which is moderately related to star rating and trip type.

Therefore, we take the related factors in the existing studies and studies in the sustainable tourism context if those factors are affected in a different context where people visit the place for experiencing the traditional-style cultures.

\section{Methodology}

Data analysis concordant to the research objectives can be divided as follow:

\subsection{Result of the DATB establishment}

By filling their personal information into the system, the tourists who were interested in traveling in Suphanburi would be provided with proper suggestions and basic information of the tourist attractions to match individuals' interest, which made making a decision easier for them. The usage of the system designed to be easy, convenient and up to standard with the dual language system could be categorized into four parts 
which are: 1) tourist attractions guidance. 2) satisfaction survey on the website. 3) survey on tourist information. 4) tourist behaviour analysis. As shown in Figure. 2 to Figure. 6, screen displays the homepage of website, tourist attractions guidance page, satisfaction survey on the website page, tourist information survey page, tourist behaviour analysis result page.

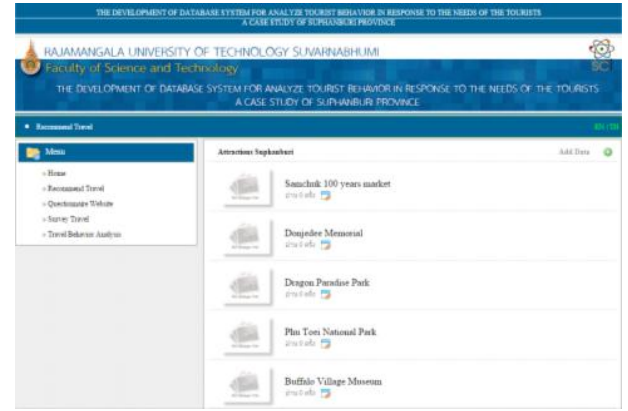

Fig. 3: Tourist attractions guidance page.

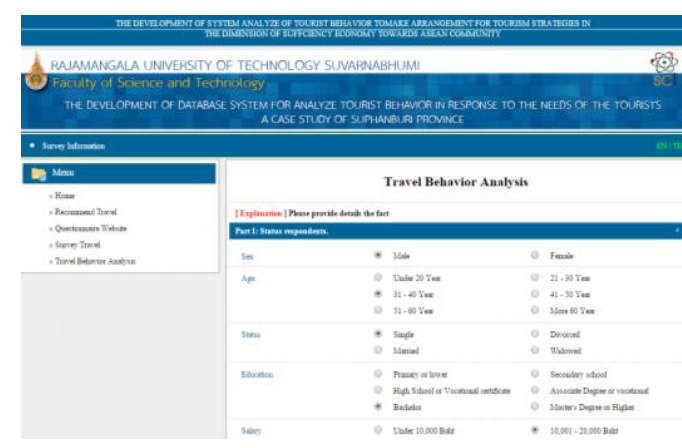

Fig. 5: Tourist information survey page.

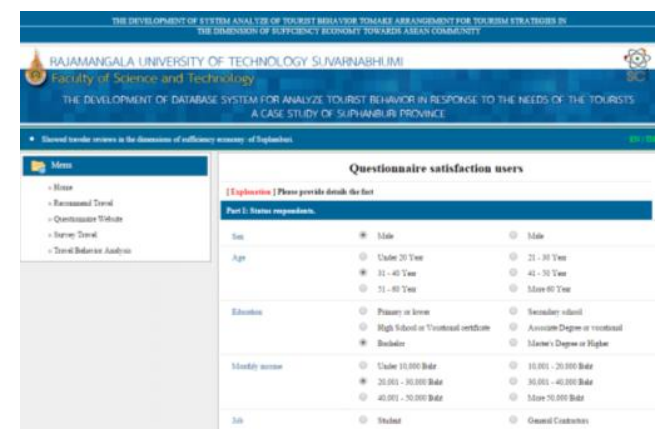

Fig. 4: Satisfaction survey on the website page.

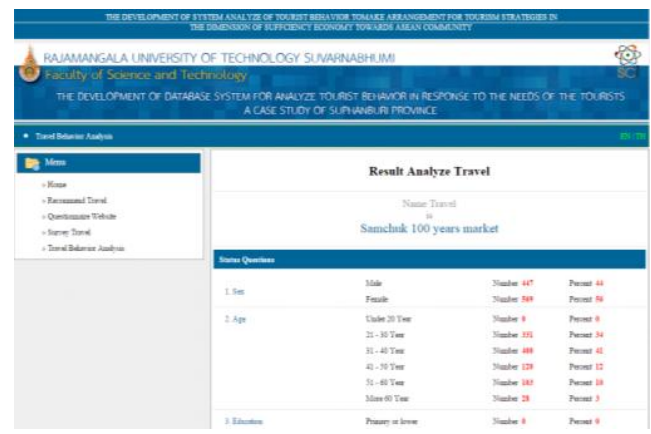

Fig. 6: Tourist behaviour analysis results in page.

\subsection{The result of satisfaction surveys analysis on the DATB}

According to the satisfaction survey on the DATB rated by the users who tried the system, this part of the analysis showed that it received the excellent feedbacks.

To find the satisfaction of the users, we used the survey as an instrument. It was in the form of the rating scale, classified into five levels. Interval scale was used to measure the overall score. Excellent 5 points, Very good 4 points, Good 3 points, Fair 2 points, Poor 1 points.

Then we calculate the average of the score and compute the significant level of user satisfaction. The calculations for significant level of user satisfaction were shown as follow: [8]

$$
\begin{aligned}
\text { Range } & =\text { Maximum point }- \text { Minimum point } \\
& =5-1 \\
& =4
\end{aligned}
$$

Class interval = Range/number of interval

$$
\begin{aligned}
& =4 / 5 \\
& =0.8
\end{aligned}
$$

The average points as follows:

4.21 - 5.00 mean the users have an excellent level of satisfaction with the system.

$3.41-4.20$ mean the users have a very good level of satisfaction with the system.

$2.61-3.40$ mean the users have a good level of satisfaction with the system.

$1.81-2.60$ mean the users have a fair level of satisfaction with the system.

$1.00-1.80$ mean the users have a poor level of satisfaction with the system.

Rating scale provides an effective method for measuring the user satisfaction, which is classified into five levels from highest (5) to lowest (1). For example, 5 mean that the user has the highest satisfaction toward the system. The surveys were answered by 100 of all the users. The results could be concluded and interpreted as follow: 
Table 1: Users' Satisfaction on the Usage of the DATB

\begin{tabular}{|c|l|c|c|c|}
\hline No. & \multicolumn{1}{|c|}{ Topics } & \multicolumn{1}{|c|}{$\begin{array}{c}\text { Point } \\
\text { Average }\end{array}$} & \multicolumn{1}{|c|}{$\begin{array}{c}\text { S.D. } \\
\text { Seaning of } \\
\text { Satisfaction }\end{array}$} \\
\hline 1. & The website is finely and appropriately designed. & 4.62 & 0.54 & Excellent \\
\hline 2. & $\begin{array}{l}\text { Data organization on the website is appropriate, easily understandable and } \\
\text { convenient to use. }\end{array}$ & 4.12 & 0.73 & Very good \\
\hline 3. & The information showed on the website is credible. & 4.35 & 0.61 & Excellent \\
\hline 4. & Website processes and shows results speedily. & 4.46 & 0.63 & Excellent \\
\hline 5. & The website is easy to use. & 4.16 & 0.74 & Very good \\
\hline 6. & Users can add, delete and/or adjust an information filled on a website efficiently. & 4.54 & 0.66 & Excellent \\
\hline 7. & Website supports country's efficiency in tourism. & 4.38 & 0.62 & Excellent \\
\hline 8. & An information provided on website is useful for assessing tourist behavior & 4.5 & 0.64 & Excellent \\
\hline 9. & Website is useful to community, society and country's economy. & 4.6 & 0.52 & Excellent \\
\hline 10. & You are overall satisfied with the DATB system. & 4.56 & 0.67 & Excellent \\
\hline & & 4.42 & 0.63 & Excellent \\
\hline
\end{tabular}

According to Table 1, the average and standard deviation of users' satisfaction with the DATB system showed that the total average was 4.42 which indicated and could be concluded that it was the highest level of satisfaction.

\section{Conclusion}

This research was to create, develop the system for analyzing behavior and the database system for publicizing tourism, study tourists' behavior before and after distributing system on a network, and find the satisfaction of users interacting with the DATB system. According to the result from the group of samples who were tourists traveling at 10 tourist attractions in Suphanburi, it showed that the database system was enable to analyze tourist behavior, suggest tourist attractions, survey tourist information, evaluate users' satisfaction on the database system for analyzing tourist behavior, and provide the result of the analysis for individuals through the dual language system efficiently and internationally. Such system was another opportunity to publicize tourism and tourist attractions, respondents to preparation for AEC that made choosing a place to travel quicker and more comfortable, the channel to distribute income to local tourist sites and related communities, the pursuit of government policies, and also the support for the tourism industry of the country. It reached the objectives and scopes of the research project.

\section{Future Plans}

The DATB system should be developed further in order to connect to tourism systems of other provinces and add value to information for tourists. The tourist attractions in Suphanburi should be increased in order to help publicizing the province, add variables to data analysis and expand the range of tourists. The development to connect system to application on mobile phones should be done as well in order that results can be accessed comfortably and quickly, enlarging the usage of online users.

\section{Acknowledgment}

This work cannot complete without the great support from all faculty staffs and students from Faculty of Science and Technology, RUS for informing the survey and give a very useful suggestion for the development of the systems. Lastly, I would like to express my gratitude to my parents, for their support and encouragement that provided the foundation for this work. If any mistake in this work I would like to welcome and will improve it in the future.

\section{References}

[1] Department of Tourism. (2015). Tourism Strategy. [Online] Retrieved 27 July 2015 From: http://www.tourismkm-asean.org/

[2] The Thailand Research Fund (2015). Thailand Research Fund Database [Online] 
From:http://www.trf.or.th/index.php?option=com_content $\&$ view=article $\&$ id=3048\&Itemid=101

[3] Sumet Tontivejakul (2006). Sufficiency Economy: A new direction of Sustainable Tourism Development. Royal Development Journal Vol. 1, 2005.

[4] Department of Tourism (2011). ASEAN Tourism Marketing Strategy 2012-2015. [Online] Retrieved 7 May 2015 From: http://www.tourismkm-asean.org/wp-content/pdf/Plan-ASEAN-Tourism/ASEANTourism-MarketingStrategy-ATMS-2012-2015.pdf

[5] Boehm, B., \& Turner, R. (2003). Balancing Agility and Discipline: A Guide for the Perplexed, Portable Documents. Addison-Wesley Professional. 26 - 54.

[6] Larman, C. (2004). Agile and iterative development: a manager's guide. Addison-Wesley Professional.

[7] Chusit Chuchart (2010). Tourism in Sufficiency Economy Aspect, Chiangmai, Wanida Publishing, pp.2-29.

[8] Jirayu Issarangkul (2003). Economics Framework of Sufficiency Economy, Bangkok, Royal Agriculture Electronic Book Project. 27-28.

[9] Thailand Tourism (2015). Suphanburi Tourism [Online] From: http://thai.tourismthailand.org/

[10] Office of Suphanburi Province (2558). Suphanburi History. [Online] From: http://www.suphanburi.go.th/suphan/ProvinceHistory.php

[11] Sumith Suwan (2013). Design of Qualitative Research. [Online] From: http://rlc.nrct.go.th/ewt_dl.php?nid=900

[12] Samaporn Kaiwichian, et al. (2550). Guideline to Tourism Development in Ban Chang Village in SouthernNortheast. Bangkok, Office of The Thailand Research Fund.

[13] Thailand's National Statistics Department (2014). Survey of Foreign Tourists in Thailand in 2014. Bangkok, Department of Tourism.

[14] Sureeporn Thamikkapong, Surangrat Pansang (2010). The Development of Sustainable Tourism for Natural Attraction in Phetchabun. Phetchabun: Phetchabun Rajabhat University.

[15] Leechai Panyawongngam (2010). Factors that Influence Tourist Industry in Bangkok. Bangkok, : Rajamangala University of Technology Krungthep.

[16] Pizam, A., \& Sussmann, S. (1995). Does nationality affect tourist behavior?.Annals of Tourism Research, 22(4), 901-917.

[17] Lew, A., \& McKercher, B. (2006). Modeling tourist movements: A local destination analysis. Annals of tourism research, 33(2), 403-423.

[18] Shoval, N., McKercher, B., Ng, E., \& Birenboim, A. (2011). Hotel location and tourist activity in cities. Annals of Tourism Research, 38(4), 1594-1612.

[19] Shoval, N., \& Isaacson, M. (2007). Tracking tourists in the digital age. Annals of Tourism Research, 34(1), 141159.

[20] Assaf, A. G., \& Agbola, F. W. (2012). Efficiency analysis of the Australian accommodation industry: A Bayesian output distance function. Journal of Hospitality \& Tourism Research, 1096348012451459.

[21] Li, M. (2012). Cross-cultural tourist research: A meta-analysis. Journal of Hospitality \& Tourism Research, 1096348012442542 .

[22] Ye, Q., Li, H., Wang, Z., \& Law, R. (2014). The influence of hotel price on perceived service quality and value in e-tourism an empirical investigation based on online traveler reviews. Journal of Hospitality \& Tourism Research,38(1), 23-39.

[23] Thailand's National Statistical Office. (August 2015). Official Statistics Thailand. [Online]. Available: http://www.nso. go.th/

[24] TAT Intelligence Center (August 2015). Tourism Authority of Thailand. [Online]. Available: http://intelligencecenter.tat.or.th/ main.php?filename=index_en.

[25] K. Wanichbuncha. Statistic for Research. $2^{\text {nd }}$ ed, Bangkok: Chulalongkorn University, 2006. 